\title{
Femoral neck fracture in children: treatment and complications
}

\author{
FRATURA dO CÓlO dO FÊMUR EM CRIANÇAS: TRATAMENTO E COMPLICAÇÕES \\ Authorship: Brazilian Society of Orthopedics and Traumatology \\ Participants: Akkari M, Santili C, Akel E, Angelim R
}

http://dx.doi.org/10.1590/1806-9282.61.01.005

The Guidelines Project, an initiative of the Brazilian Medical Association, aims to combine information from the medical field in order to standardize procedures to assist the reasoning and decision-making of doctors.

The information provided through this project must be assessed and criticized by the physician responsible for the conduct that will be adopted, depending on the conditions and the clinical status of each patient.

\section{Description OF the EVIDENCE COLECTION METHOD}

Searches were conducted in the Medline database. The MeSH (Medical Subject Heading Terms) key-words used for the search were: "femoral neck", "fractures/surgery", "child", "femoral neck fracture/complications", "decompression surgical", "internal fixation". Thus, questions related to the topic were developed with a focus on the following aspects: types of treatment; best time to therapeutic approach; and ideal treatment with lower complication rates. Based on this, the questions were structured using PICO (pacient, intervention, comparison, outcome) methodology, and the search began with the selection of papers with better strength of scientific evidence.

\section{Degree of eVidence ReCOMmendation}

A. Experimental or observational studies of higher consistency.

B. Experimental or observational studies of lower consistency.

C. Case reports (non-controlled studies).

D. Opinions without critical evaluation, based on consensus, physiological studies, or animal models.

\section{Овjective}

To develop a guideline for the treatment of femoral neck fracture in children, which can help orthopedists to manage rapidly and accurately this type of fractures aiming at correct treatment and fewer complications based on the best available scientific evidence.

\section{Conflict Of InTERest}

No conflict of interest informed.

\section{INTRODUCTION}

Proximal femoral fractures in children are relatively rare events, accounting for about $1 \%$ of all fractures in chil- dhood. Trauma mechanisms derive mostly from high-energy trauma (80 to 90\%) and less frequently from low-energy trauma or disease states. ${ }^{1}$ Classification is based on the location of the fracture line, being the most used for this type of fracture the Delbet system (1907), later popularized by Colonna (1929), which divides fractures in types I, II, III and IV, which may assist in treatment decision-making, in addition to being a predictor of risk for complications. ${ }^{2}$ Major complications occur especially due to interference with local growth, and due to vascularization and consolidation disorders. ${ }^{2}$ These complications include avascular necrosis (AVN), pseudoarthrosis, coxa vara and limb shortening. The subject is important due to the fact that these are serious fractures, both in terms of trauma mechanism involved and frequent complications and disabling sequelae. Therefore, it is an orthopedic emergency that requires a fast and accurate strategy in order to reduce complications to a minimum, and thus the costs associated with treatment and rehabilitation of these patients. ${ }^{1,2}$

\section{WhICH ARE THE MOST RELEVANT RISK FACTORS FOR THE DEVELOPMENT OF AVASCULAR NECROSIS AFTER FEMORAL NECK FRACTURES?}

Among the complications associated with femoral neck fractures in children, avascular necrosis (AVN) is the most worrying. It is important to identify predictive risk factors for AVN in this type of trauma. Type of fracture, the patient's age, occurrence of deviation and the quality of reduction are all indicators for risk of AVN $(\mathbf{A}, \mathbf{B}))^{3,4}$ Regarding the type of fracture, type IV fractures have a lower incidence of AVN compared with the other types. Compared to type IV fractures according to Delbet's classification, fracture types I, II and III show respectively 14.5, 6.5 and 3.7 higher chances of developing AVN. Regarding age, it has been noticed that it is directly proportional to the risk of $A V N$, and the risk rises to a ratio of 1:14 for each year of 
life, i.e. older children have higher risk compared to younger children (A). ${ }^{3}$ With regard to deviation, we found no quantification of the risk, but there is a directly proportional relationship of AVN in patients with larger deviations (B). ${ }^{4}$ Also, in terms of quality of reduction, anatomical reductions are related to lower rates of $\operatorname{AVN}(\mathbf{B}){ }^{4}$

\section{Recommendation}

There is no way to predict with certainty which patients will develop AVN; however, age, type of fracture, degree of deviation and quality of reduction were the factors most correlated. Therefore, these variables must be considered in treatment planning and patient follow-up.

\section{SURGICAL OR CONSERVATIVE TREATMENT?}

Several treatment methods are described in the literature, from non-surgical treatments including closed reduction and immobilization in a cast, to cases of open reduction with internal fixation and osteotomies. This reflects a huge concern to avoid late sequelae of a poorly planned treatment. It is known that both quality of reduction and stabilization of fractures are essential to a successful outcome. It is recommended to perform early treatment within 24 hours of the trauma event, and internal fixation with Kirschner wires or screws (B)..$^{5-7}$ Using Ratliff $(\mathbf{C})^{8}$ evaluation criteria, which are based on clinical and radiological data after treatment, better results may be seen in patients undergoing internal fixation, regardless of the type of osteosynthesis used (B). ${ }^{5-7,9}$ In a retrospective study, $69.3 \%$ of the results were good in surgically treated patients, compared with $17 \%$ for patients treated in a closed manner $(\mathbf{B}){ }^{9}$

\section{Recommendation}

Studies show that surgical treatment with fracture fixation produces better results, and thus this is the recommended treatment.

\section{WHAT KIND OF REDUCTION (OPEN OR CLOSED) IS MOST APPROPRIATE IN THIS TYPE OF FRACTURE?}

Many methods of treatment for proximal femoral fractures in children have been described; however, some have become obsolete over the years. With increased understanding of these injuries and studies performed on fracture management, the aim is currently that of treatment with anatomical reduction and focus stability. Closed treatment has become the exception. Based on other studies, one can prove the benefit of anatomical reductions to prevent complications. Some factors may determine the approach to be used (open or closed). Difficulty in achieving closed reduction may determine a change to open reduction. The important thing in this situation is not to damage the vascularization even more with untimely and fruitless maneuvers. Another important point is the availability of suitable materials such as radioscopy, which facilitate reduction and fixation without opening the fracture focus. Recent studies show better results with an open approach, but we must consider that these procedures usually lead to anatomical reduction $(\mathbf{B}) \cdot{ }^{10,11}$

\section{Recommendation}

Open reduction should always be considered when it is difficult to achieve a satisfactory closed reduction.

\section{DOES EARLY HIP DECOMPRESSION REDUCE THE RISK OF AVASCULAR NECROSIS?}

The blood supply to the head and neck of the femur in children, unlike adults, receives little contribution from the round ligament artery. The main source of blood supply is through lateral epiphyseal vessels and upper and lower metaphyseal vessels, all branches of the medial circumflex artery. A deviated fracture can cut the intra bone vascular supply, and produce a synovial rupture by severing the metaphyseal and epiphyseal lateral branches. This initial damage is not correctable since it occurred in the event of trauma $(\mathbf{C}){ }^{2}$ Once the fracture occurs, it is possible, however, to reduce the risk of premature AVN through early decompression of hemarthrosis (24-36 hours after trauma) done by joint aspiration (B). ${ }^{12}$ Hemarthrosis also contributes to the genesis of AVN, as it buffers the vessels, contributing to necrosis, which is evidenced by some authors as a lower rate of $\mathrm{AVN}$ after decompression $(\mathbf{B})$. $^{5,7,13,14}$

\section{Recommendation}

Based on evidence that the decompression of the articular hematoma leads to lower rates of AVN, it should be performed as soon as possible.

\section{What is the maximum time between the ACCIDENT AND EARLY THERAPEUTIC APPROACH TO MINIMIZE THE MOST COMMON COMPLICATIONS?}

Femoral neck fractures in children are serious and also associated with high rates of complications. Since the beginning of treatment, we must act to prevent early and late complications. Therefore, anatomical reduction and internal fixation performed on an urgent basis have been recommended for therapeutic success $(\mathbf{B}) .^{9}$ Some studies have shown higher rates of good results in patients treated within the first 24 hours after trauma $(\mathbf{B}) .^{9,15-18}$ 


\section{Recommendation}

Based on published studies, surgery should be performed as soon as possible and ideally within the first 24 hours.

\section{RefEREnCES}

1. McCarthy J, Noonan K. Fractures and traumatic dislocations of the hip in children. In: Rockwood and Wilkins' Fractures in Children, $7^{\text {th }}$, Beaty JH, Kasser J. (Eds), Lippincott Williams \& Wilkins, Philadelphia 2010. p.769.

2. Herring JA. Hip fractures. In: Tachdijan's Pediatric Orthopedics: From the Texas Scottish Rite Hospital for Children, $4^{\text {th }}$, Saunders Elsevier, Philadelphia 2008. Vol 3.

3. Moon ES, Mehlman CT. Risk factors for avascular necrosis after femoral neck fractures in children: 25 Cincinnati cases and meta-analysis of 360 cases. J Orthop Trauma. 2006;20(5):323-9.

4. Morsy HA. Complications of fracture of the neck of the femur in children. A long-term follow-up study. Injury. 2001;32(1):45-51.

5. Cheng JC, Tang N. J. Decompression and stable internal fixation of femoral neck fractures in children can affect the outcome. Pediatr Orthop. 1999;19(3):338-43.

6. Quinlan WR, Brady PG, Regan BF. Fracture of the neck of the femur in childhood. Injury. 1980;11(3):242-7.

7. Matejka J, Pavelka T, Kostál J, Cervenková H. Long-term results following fracture of the femoral neck in children. Acta Chir Orthop Traumatol Cech. 2005;72(2):98-104. Czech.

8. Ratliff AH. Fractures of the neck of the femur in children. J Bone Joint Surg Br. 1962;44-B:528-42
9. Astur DC, et al. Correlação entre os índices de necrose e a estabilização precoce nas fraturas da extremidade proximal do fêmur na infância. Rev. bras. ortop. [online]. 2010, vol.45, n.4 [cited 2012-11-26], pp. 426-32.

10. Song KS. Displaced fracture of the femoral neck in children: open versus closed reduction. J Bone Joint Surg Br. 2010;92(8):1148-51.

11. Bali K, Sudesh P, Patel S, Kumar V, Saini U, Dhillon MS. Pediatric femoral neck fractures: our 10 years of experience. Clin Orthop Surg. 2011;3(4):302-8. Epub 2011 Dec 1.

12. Ng GP, Cole WG. Effect of early hip decompression on the frequency of avascular necrosis in children with fractures of the neck of the femur. Injury. 1996;27(6):419-21.

13. Pförringer W, Rosemeyer B. Fractures of the hip in children and adolescents. Acta Orthop Scand. 1980;51(1):91-108.

14. Varshney MK, Kumar A, Khan SA, Rastogi S. Functional and radiological outcome after delayed fixation of femoral neck fractures in pediatric patients. J Orthop Traumatol. 2009;10(4):211-6

15. Bombaci H, Centel T, Babay A, Türkmen IM. 2. Evaluation of complications of femoral neck fractures in children operated on at least 24 hours after initial trauma. Acta Orthop Traumatol Turc. 2006;40(1):6-14. Turkish.

16. Flynn JM, Wong KL, Yeh GL, Meyer JS, Davidson RS. Displaced fractures of the hip in children. Management by early operation and immobilisation in a hip spica cast. J Bone Joint Surg Br. 2002;84(1):108-12.

17. Shrader MW, Jacofsky DJ, Stans AA, Shaughnessy WJ, Haidukewych GJ. Femoral neck fractures in pediatric patients: 30 years experience at a level 1 trauma center. Clin Orthop Relat Res. 2007;454:169-73.

18. Swiontkowski MF, Winquist RA. Displaced hip fractures in children and adolescents. J Trauma. 1986;26(4):384-8. 